\title{
Caspase Recruitment Domain (CARD) as a Bi-functional Switch of Caspase Regulation and NF- $\kappa$ B Signals
}

\author{
Gil-Sun Hong and Yong-Keun Jung* \\ Department of Life Science, Kwangju Institute of Science and Technology, Puk-gu, Kwangju 500-712, Korea
}

Received 7 December 2001

\begin{abstract}
Over the last three years, increasing numbers of adaptor molecules that contain the caspase recruitment domain (CARD) have been identified. CARD was originally described as a protein-binding motif that interacts with caspase through a CARD-CARD interaction. However, CARD has now also been found in many adaptor proteins that do not interact with caspase, but mediate the assembly of CARD-containing proteins in apoptosis and NF- $\mathrm{KB}$ signaling. Apoptotic signaling is controlled by homo- and heterophilic interactions between CARD-containing molecules: Caspases exist as inactive zymogens, and are activated through interactions with adaptor molecules that contain CARD. CARD-containing molecules are also involved in the regulation of gene expression that is involved in cell survival and immune responses through NF- $\kappa \mathrm{B}$ activation. Therefore, this report will describe the function and signaling cascade of recently identified CARD-containing proteins in apoptosis and NF-KB activation. CARD-containing molecules were divided into two major groups, based on their functional interactions with caspase and NF-KB signals (Fig. 1 and Table 1).
\end{abstract}

\section{CARD-adaptor in NF- $\mathrm{NB}$ activation}

Frequent mutation in tumors affecting $N F-\kappa B$ activation and apoptosis

Bcl10/CLAP/CIPER/mE10/CARMEN Bcl10 was recently cloned from the chromosome translocation $\mathrm{t}(1 ; 14)$ (p22; q32) in MALT B cell lymphoma. Inactivating mutations and the over-expression of Bcl10 were also frequently found in the lymphoid tumor of the B or T cell lineage, as well as cell lines that are derived from solid tumor types (Fakruddin et al., 1999; Lee et al., 1999; Willis et al., 1999; Zhang et al., 1999). This indicates that Bcl10 may be involved in the development of human malignancy. Bcl10 was also identified as CIPER by

*To whom correspondence should be addressed.

Tel: 82-62-970-2492; Fax: 82-62-970-2484

E-mail: ykjung@kjist.ac.kr
Koseki et al. (1999), mE10 by Yan et al. (1999), and CLAP by Srinivasa et al. (1999).

Bcl10 contains an N-terminal CARD and a C-terminal region that is rich in serine and threonine residues (STR) (Fig. 1). When overexpressed, Bcl10 activated NF- $\mathrm{BB}$, which caused apoptosis of the transfected cells and suppressed transformation. However, the mutation of Bcl10 could not induce cell death, or activate NF- $\mathrm{BB}$. This indicates that the loss of Bcl10 may confer a survival advantage to cells (Willis et al., 1999). Bcl10 forms homodimers, and interacts via its CARD with other CARD-containing molecules (including viral E10), but the binding of Bcl10 to caspase-9 needs to be further characterized (Koseki et al., 1999; Yan et al., 1999).

Recently, an analysis of $\mathrm{Bcl} 10^{-/-}$mice demonstrated that Bcl10 was a positive regulator of antigen receptor-induced activation of NF-KB (Ruland et al., 2001). One-third of the $\mathrm{Bcl10}^{-/}$embryos developed embryonic lethality, and the $\mathrm{Bcl10}^{-/}$cells retained their susceptibility to various apoptotic stimuli, while an altered sensitivity to apoptosis was described in Bcl10 transgenic mice (Yoneda et al., 2000). However, severe immunodeficiency was observed in the surviving $\mathrm{Bcl10}^{-/-}$mice. Also, the antigen receptor or PMA/Ionomycininduced NF- $\kappa \mathrm{B}$ activation was defective in $\mathrm{Bcll}^{-/}$ lymphocytes. Theses observations suggest that Bcl10 connects the antigen receptor signaling to NF- $\mathrm{BB}$ activation in B and T cells (Ruland et al., 2001).

Signaling net work mediated by CARD-CARD interactions

CARD9, CARD10/Carma3, CARD11/Carma1, CARD14/

Carma2 While the upstream signaling pathway that links Bcl10 to extracellular receptors is not well-characterized, Bcl10 associates with many CARD-containing adaptor proteins, mainly through the CARD motif. Bcl10 binds CARD11 and CARD14, another CARD-containing membrane-associated guanylate kinase (MAGUK) family member (Bertin et al., 2001) (Table 1). CARD11 and CARD14 consist of an N-terminal CARD domain, a central coiled-coil domain, and a C-terminal tripartite domain that is 
Fig. 1. Schematic diagram showing respective domains of CARD-containing proteins.

comprised of a PDZ domain, a Src homology 3 domain (SH3), and a GUK domain with homology to the guanylate kinase (Bertin et al., 2001) (Fig. 1). MAGUK family proteins are known to function as molecular scaffolds for the assembly of protein complexes. Interestingly, the expression of CARD11 and CARD14 induced the phosphorylation of Bcl10 and NF- $\kappa B$ activation. This suggests that CARD11 and CARD14 may function as upstream activators of Bcl10.

While CARD10 also belongs to the MAGUK family that interacts with $\mathrm{Bcl10}$ and activates NF- $\mathrm{KB}$, its ability to phosphorylate Bcl10 is still unknown (Wang et al., 2001). In addition, CARD9, another CARD protein that interacts with Bcl10 and activates NF- $\mathrm{BB}$, shows a similar structure with the MAGUK family, but lacks the tripartite structure at its Cterminal region (Bertin et al., 2000) (Fig. 1). Though the functional significance of this modification is unclear, Yui et al. (2001) recently suggested that Bcl10 phosphorylation regulated its apoptotic activity. The phosphorylation of Bcl10 caused Bcl10 to bind cIAPs, and the Bcl10 mutant defective binding to cIAPs could not induce apoptosis (Yui et al., 2001). Therefore, considering the observations that show the role of E10-mediated hyperphosphorylation of Bcl10 for NF- $\mathrm{KB}$ activation (Thome et al., 2001), the modification of Bcl10 seems to be associated with the regulation of apoptosis and $\mathrm{NF}-\kappa \mathrm{B}$ activation.

$$
\text { CARD11, } 14 \rightarrow \text { Bcl10-(p) } \rightarrow \text { apoptosis \& NF- } \kappa \text { B }
$$$$
\text { CARD9, CARD10? - - }
$$

Nod1/CARD4 and Nod2/CARD15 Recent studies identified new members of the Apaf-1 family, which is a mammalian counterpart of $C$. elegance CED4, an important apoptosis regulator. Nod1 and Nod2 are Apaf-1-like molecules that are composed of CARD, nucleotide-binding domain (NBD), and leucine-rich repeats (LRR) (Inhara et al., 1999; Liu et al., 
Table 1. CARD-containing proteins.

\begin{tabular}{|c|c|c|}
\hline Protein & Function & Binding partner \\
\hline \multicolumn{3}{|l|}{ Caspase Regulation } \\
\hline Pseudo-ICE/ COP/ CARD16 & Inhibitor of caspase- 1 activation & caspase-1, RIP2 \\
\hline ICEBERG & Inhibitor of caspase- 1 activation & caspase-1 \\
\hline CARD12/ CLAN/ Ipaf-1 & Regulator of caspase- 1 activation & ASC, caspase-1, Nod2, CARD7, Bcl10 \\
\hline DEFCAP/ CARD7/ NAC & Regulator of caspase- 2 activation & caspase- $2,-9$ \\
\hline Apaf-1 & Regulator of caspase- 9 activation & caspase- 9 \\
\hline CARD8/ TUCAN/ CARDINAL & $\begin{array}{l}\text { Negative regulator of caspase- } 9 \text { and/or } \\
\text { NF- } \kappa B \text { activation }\end{array}$ & caspase- 9 \\
\hline ARC & Inhibitor of caspase- 8 activation & caspase- $2,-8$ \\
\hline ASC (?) & Pro-apoptotic & \\
\hline \multicolumn{3}{|l|}{ CARD-adaptor family in NF- $\mathrm{KB}$ activation } \\
\hline RIP2/ RICK/ CADIAK & $\mathrm{NF}-\kappa \mathrm{B}$ activation & $\begin{array}{l}\text { cIAP-1, TRAF-1, -5, -6, Nod1, CARD8, } \\
\text { CARD16, p75 }\end{array}$ \\
\hline Bcl10/ CLAP/ CIPER/ mE10/ CARMEN & $\mathrm{NF}-\kappa \mathrm{B}$ activation & CARD9, 10, 11, 12, 14 \\
\hline Nod1/ CARD4 & NF- $\kappa B$ activation, caspase- 9 activation & caspase-9 and RIP2 \\
\hline Nod2/CARD15 & $\mathrm{NF}-\kappa \mathrm{B}$ activation & RIP2 \\
\hline CARD9 & $\mathrm{NF}-\kappa \mathrm{B}$ activation & Bcl10 \\
\hline CARD10/ Carma3 & $\mathrm{NF}-\kappa \mathrm{B}$ activation & Bcl10 \\
\hline CARD11/ Carma1 & NF- $\kappa B$ activation & Bcl10 \\
\hline CARD14/ Carma2 & $N F-\kappa B$ activation & Bcl10 \\
\hline
\end{tabular}

1999; Ogura et al., 2001) (Fig. 1). Nod1 and Nod2 may regulate both apoptosis and NF- $\mathrm{KB}$ activation (Inhara et al., 1999). Nod1 bound to the prodomain of caspases and promoted caspase-9-induced apoptosis (Inhara et al., 1999; Liu et al., 1999). Unlike Apaf-1, however, Nod1 and Nod2 induced the activation of NF- $\mathrm{BB}$ through its LRR motif that interacts with the CARD-containing kinase RIP2 (Table 1). Self-association of Nod1 induced the interaction of the associated RIP2/RICK with IKK- $\gamma$, which activated NF- $\kappa B$ (Liu et al., 1999; Ogura et al., 2001).

In contrast to Nod1, the expression of Nod2 is highly restricted to monocytes. Frameshift and missense mutations of Nod2 were reported in Crohn's disease, a chronic inflammatory disorder of the gastrointestinal tract (Ogura et al., 2001) and in the Blau syndrome, a second granulomatous disorder (Miceli-Richard et al., 2001), respectively. Loss of the function mutation of the Nod2 gene that is found in Crohn's disease produces a truncated protein that is defective in NF- $\kappa \mathrm{B}$ activation (Ogura et al., 2001), indicating the important role of Nod2 in pathogenesis.

NF- $\mathrm{BB} \leftarrow$ Nod1, Nod2 $\rightarrow$ caspase- 9

RIP2/RICK/CARDIAK RIP2 is homologous to RIP that is a component of both the TNFR-1 and CD40 signaling. RIP2 contains an N-terminal domain that is homologous to Ser/Thr kinases and a C-terminal CARD (McCarthy et al., 1998) (Fig. 1). RIP2 was implicated in the activation of NF- $\mathrm{KB}$ and cell death. The pro-apoptotic function of RIP2 was restricted to its C-terminal CARD, whereas the intact molecule was necessary for NF-אB activation (McCrathy et al., 1998). RIP2 interacts with cIAP1 and TRAFs in TNF-R1 signaling (McCarthy et al., 1998) and with CLARP, a caspase-like molecule that is known to bind to FADD and caspase-8 in CD95-mediated apoptosis (Inohara et al., 1998) (Table 1). RIP2 also binds to the death domain of the p75 nerve growth factor-receptor via its CARD domain in order to induce death in a subset of cell types (Khursigara et al., 2001). These observations implicate that RIP2 is recruited to the receptor-signaling complexes in order to regulate the signals that lead to NF- $\mathrm{KB}$ activation and apoptosis (Inohara et al., 1998; McCarthy et al., 1998; Navas et al., 1999).

$\mathrm{NF}-\kappa \mathrm{B} \leftarrow \mathrm{RIP} 2 / \mathrm{RICK} / \mathrm{CARDIAK} \rightarrow \mathrm{CLARP} \rightarrow$ caspase- 8

\section{CARD-adaptor in caspase regulation}

Pseudo-ICE/COP/CARD16 and ICEBERG Pseudo-ICE and ICEBERG show a 92\% and 53\% sequence identity, respectively, to the prodomain of caspase-1 (Druilhe et al., 2001; Lee et al., 2001). Pseudo-ICE binds to both RIP2 and the prodomain of caspase-1, and inhibits RIP2-induced caspase-1 oligomerization and processing for its activation (Lee et al., 2001; Druilhe et al., 2001). ICEBERG is similar to Pseudo-ICE, and it prevents the association of caspase-1 with RIP2, thereby its activation (Humke et al., 2000; Druilhe et al., 2001). These observations indicate that Pseudo-ICE and ICEBERG are intracellular regulators that play a role in down-regulating inflammatory responses through the negative feedback loop. Furthermore, like caspase-1, Pseudo-ICE, but 
not ICEBERG, interacts with the CARD-containing kinase RIP2 and activates NF- $\kappa B$ (Table 1). This suggests that Pseudo-ICE and ICEBERG are intracellular regulators of NF$\kappa \mathrm{B}$ activation during the inflammatory response.

$\mathrm{NF}-\kappa \mathrm{B} \leftarrow$ Pseudo-ICE/COP/CARD16, ICEBERG-1 caspase-1

CARD12/Ipaf-1/CLAN CARD12 is composed of an Nterminal CARD, NBS, and C-terminal LRR (Fig. 1). The CARD domain of CARD12 interacts selectively with the CARD domain of ASC and caspase-1. As suggested, it may also be involved in the activation of caspase- 1 in response to inflammatory and apoptotic stimuli (Poyet et al., 2001; Geddes et al., 2001; Damiano et al., 2001). This indicates that CARD12 contributes to a number of intracellular processes, including apoptosis and the inflammatory response, including cytokine processing.

CARD12/Ipaf-1/CLAN $\rightarrow$ ASC, caspase-1

DEFCAP/NAC/CARD7 Similar to Apaf-1 and Nod1, DEFCAP contains CARD and NBD, but unlike Apaf-1 and Nod1, it contains pyrim-like motif (PLM) and a proline-rich sequence (PR) at its N-terminus (Hlaing et al., 2001) (Fig. 1). The PLM of DEFCAP is conserved with other apoptotic relating molecules, such as ASC. CARD of DEFCAP also interacts with caspase-2 and caspase-9. Alternative splicing of DEFCAP generates two splice-variants-long (L) and short (S) forms. Overexpression of DEFCAP-L, but not of DEFCAP-S, induced significant levels of apoptosis, whereas only the CARD or NBD of NAC suppressed Apaf-1-dependent apoptosis (Chu et al., 2001).

CARD7/DEFCAP/NAC $\rightarrow$ caspase-2

CARD8/TUCAN/CARDINAL CARD8 contains a CARD motif to the C-terminus like DEFCAP and RIP2 (BouchierHayes et al., 2001; Pathan et al., 2001) (Fig. 1). Interestingly, CARD8 failed to promote apoptosis or NF- $\mathrm{KB}$ activation, but rather inhibited Apaf-1/caspase-9-mediated apoptosis and NF$\kappa \mathrm{B}$ activation that is triggered by the forced-expression of TRAIL-R, RIP, Bcl10, IL-1R, or TNF-R via an interaction with IKK- $\gamma$ (Bouchier-Hayes et al., 2001; Pathan et al., 2001). Together with the up-regulation of CARD8 in some types of cancer, CARD8 as a negative regulator of apoptosis and NF$\kappa \mathrm{B}$ activation may contribute to tumorigenesis.

NF- $\kappa \mathrm{B} \mid$ - CARD8/TUCAN/CARDINAL - Apaf-1/caspase-9

ARC ARC contains a N-terminal CARD that is fused to a $\mathrm{C}$-terminal region that is rich in proline/glutamic acid residues (Koseki et al., 1998) (Fig. 1). The expression of ARC was detected in the heart and muscle, and likely regulates cell death that is induced by a variety of death signals. ARC inhibited cell death that is induced by death receptor signaling (probably via an interaction with caspase-8) and suppressed caspase-independent events (including oxidant stress) by preserving the mitochondrial function (Neuss et al., 2001).
ASC ASC is a CARD-containing proapoptotic molecule that forms insoluble aggregates during apoptosis. ASC contains a CARD motif in its C-terminal half and PLM in the N-terminus (Masumoto et al., 1999; Richards et al., 2001) (Fig. 1). ASC interacts with pyrin, the product of the MEFV locus of familial Mediterranean fever, whose patients suffer sporadic inflammatory attacks (Richards et al., 2001). Thus, through linking pyrin to ASC-mediated apoptosis, the modulation of cell survival via ASC may be a component of familial Mediterranean fever (Richards et al., 2001).

Many CARD-containing proteins have been identified from the mutation screening studies. However, the CARD-CARD binding assays and their roles in the signaling still need to be solved. Analyzing their activities in apoptosis network and $\mathrm{NF}-\kappa \mathrm{B}$ activation will be crucial to understanding the finetuning mechanism that regulates cell death and survival.

Acknowledgments We thank Ha-Na Woo for the critical reading of this manuscript. This work was supported by the National Research Laboratory Program (To Y. Jung) from the Korea Ministry of Science and Technology.

\section{References}

Bertin, J., Nir, W. J., Fischer, C. M., Tayber, O. V., Errada, P. R., Grant, J. R., Keilty, J. J., Gosselin, M. L., Robison, K. E., Wong, G. H., Glucksmann, M. A. and DiStefano, P. S. (1999) Human CARD4 protein is a novel CED-4/Apaf-1 cell death family member that activates NF- $\mathrm{\kappa B}$. J. Biol. Chem. 274, 12955-8.

Bertin, J., Guo, Y., Wang, L., Srinivasula, S. M., Jacobson, M. D., Poyet, J. L., Merriam, S., Du, M. Q., Dyer, M. J., Robison, K. E., DiStefano, P. S. and Alnemri, E. S. (2001) CARD9 is a novel caspase recruitment domain-containing protein that interacts with Bcl10/CLAP and activates NF-kappaB. J. Biol. Chem. 275, 41082-6.

Bertin, J., Nir, W. J., Fischer, C. M., Tayber, O. V., Errada, P. R., Grant, J. R., Keilty, J.J., Gosselin, M. L., Robison, K. E., Wong, G. H., Glucksmann, M. A. and DiStefano, P. S. (1999) Human CARD4 protein is a novel CED-4/Apaf-1 cell death family member that activates NF- $\kappa$ B. J. Biol. Chem. 274, 12955-8.

Bertin, J., Wang, L., Guo, Y., Jacobson, M. D., Poyet, J. L., Srinivasula, S. M., Merriam, S., DiStefano, P. S. and Alnemri, E. S. (2001) CARD11 and CARD14 are novel caspase recruitment domain (CARD)/membrane-associated guanylate kinase (MAGUK) family members that interact with Bcl10 and activate NF-kappaB. J. Biol. Chem. 276, 11877-82.

Bouchier-Hayes, L., Conroy, H., Egan, H., Adrain, C., Creagh, E. M., MacFarlane, M. and Martin, S. J. (2001) CARDINAL, a novel caspase recruitment domain protein, is an inhibitor of multiple NF- $\mathrm{KB}$ activation pathways. J. Biol. Chem. 276, 44069-77.

Chu, Z. L., Pio, F., Xie, Z., Welsh, K., Krajewska, M., Krajewski, S., Godzik, A. and Reed, J. C. (2001) A novel enhancer of the 
Apaf1 apoptosome involved in cytochrome c-dependent caspase activation and apoptosis. J. Biol. Chem. 276, 9239-45.

Damiano, J. S., Stehlik, C., Pio, F., Godzik, A. and Reed, J. C. (2001) CLAN, a novel human CED-4-like gene. Genomics 75, 77-83.

Druilhe, A., Srinivasula, S. M., Razmara, M., Ahmad, M. and Alnemri, E. S. (2001) Regulation of IL-1beta generation by Pseudo-ICE and ICEBERG, two dominant negative caspase recruitment domain proteins. Cell Death Differ. 8, 649-57.

Fakruddin, J. M., Chaganti, R. S. and Murty, V. V. (1999) Lack of Bcl10 mutations in germ cell tumors and B cell lymphomas. Cell 97, 683-4.

Geddes, B. J., Wang, L., Huang, W. J., Lavellee, M., Manji, G. A., Brown, M., Jurman, M., Cao, J., Morgenstern, J., Merriam, S., Glucksmann, M. A., DiStefano, P. S. and Bertin, J. (2001) Human CARD12 is a novel CED4/Apaf-1 family member that induces apoptosis. Biochem. Biophys. Res. Commun. 284, 7782.

Hlaing, T., Guo, R. F., Dilley, K. A., Loussia, J. M., Morrish, T. A., Shi, M. M., Vincenz, C. and Ward, P. A. (2001) Molecular cloning and characterization of DEFCAP-L and $-\mathrm{S}$, two isoforms of a novel member of the mammalian Ced-4 family of apoptosis proteins. J. Biol. Chem. 276, 9230-8.

Humke, E. W., Shriver, S. K., Starovasnik, M. A., Fairbrother, W. J. and Dixit, V. M. (2000) ICEBERG: a novel inhibitor of interleukin-1beta generation. Cell 103, 99-111.

Inohara, N., Koseki, T., del Peso, L., Hu, Y., Yee, C., Chen, S., Carrio, R., Merino, J., Liu, D., Ni, J., and Nunez, G. (1999) Nod1, an Apaf-1-like activator of caspase-9 and nuclear factorкB. J. Biol. Chem. 274, 14560-7.

Inohara, N., Koseki, T., Lin, J., del Peso, L., Lucas, P. C., Chen, F. F., Ogura, Y. and Nunez, G. (2000) An induced proximity model for NF-kappaB activation in the Nod1/RICK and RIP signaling pathways. J. Biol. Chem. 275, 27823-31.

Inohara, N., del Peso, L., Koseki, T., Chen, S. and Nunez, G. (1998) RICK, a novel protein kinase containing a caspase recruitment domain, interacts with CLARP and regulates CD95-mediated apoptosis. J. Biol. Chem. 273, 12296-300

Inohara, N., Koseki, T., del Peso, L., Hu, Y., Yee, C., Chen, S., Carrio, R., Merino, J., Liu, D., Ni, J. and Nunez, G. (1999) Nod1, an Apaf-1-like activator of caspase-9 and nuclear factorкB. J. Biol. Chem. 274, 14560-7.

Khursigara, G., Bertin, J., Yano, H., Moffett, H., DiStefano, P. S. and Chao, M. V. (2001) A prosurvival function for the p75 receptor death domain mediated via the caspase recruitment domain receptor-interacting protein 2. J. Neurosci. 21, 5854-63.

Koseki, T., Inohara, N., Chen, S. and Nunez, G. (1998) ARC, an inhibitor of apoptosis expressed in skeletal muscle and heart that interacts selectively with caspases. Proc. Natl. Acad. Sci. USA 95, 5156-60.

Koseki, T., Inohara, N., Chen, S., Carrio, R., Merino, J., Hottiger, M. O., Nabel, G. J. and Nunez, G. (1999) CIPER, a novel NF$\kappa \mathrm{B}$-activating protein containing a caspase recruitment domain with homology to Herpesvirus-2 protein E10. J. Biol. Chem. 274, 9955-61.

Lee, S. H., Stehlik, C. and Reed, J. C. (2001) Cop, a caspase recruitment domain-containing protein and inhibitor of caspase1 activation processing. J. Biol. Chem. 276, 34495-500.

Masumoto, J., Taniguchi, S., Ayukawa, K., Sarvotham, H.,
Kishino, T., Niikawa, N., Hidaka, E., Katsuyama, T., Higuchi, T. and Sagara, J. (2001) ASC, a novel 22-kDa protein, aggregates during apoptosis of human promyelocytic leukemia HL-60 cells. J. Biol. Chem. 274, 33835-8.

McCarthy, J. V., Ni, J. and Dixit, V. M. (1998) RIP2 is a novel NF-KB-activating and cell death-inducing kinase. J. Biol. Chem. 273, 16968-75.

Miceli-Richard, C., Lesage, S., Rybojad, M., Prieur, A. M., Manouvrier-Hanu, S., Hafner, R., Chamaillard, M., Zouali, H., Thomas, G. and Hugot, J. P. (2001) CARD15 mutations in Blau syndrome. Nature Genet. 29, 19-20.

Neuss, M., Monticone, R., Lundberg, M. S., Chesley, A. T., Fleck, E. and Crow, M. T. (2001) The apoptotic regulatory protein ARC (apoptosis repressor with caspase recruitment domain) prevents oxidant stress-mediated cell death by preserving mitochondrial function. J. Biol. Chem. 276, 33915-22.

Ogura, Y., Bonen, D. K., Inohara, N., Nicolae, D. L., Chen, F. F., Ramos, R., Britton, H., Moran, T., Karaliuskas, R., Duerr, R. H., Achkar, J. P., Brant, S. R., Bayless, T. M., Kirschner, B. S., Hanauer, S. B., Nunez, G. and Cho, J. H. (2001) A frameshift mutation in NOD2 associated with susceptibility to Crohn's disease. Nature 411, 603-6.

Ogura, Y., Inohara, N., Benito, A., Chen, F. F., Yamaoka, S. and Nunez, G. (2001) Nod2, a Nod1/Apaf-1 family member that is restricted to monocytes and activates NF-אB. J. Biol. Chem. 276, 4812-8.

Pathan, N., Marusawa, H., Krajewska, M., Matsuzawa, S., Kim, H., Okada, K., Torii, S., Kitada, S., Krajewski, S., Welsh, K., Pio, F., Godzik, A. and Reed, J. C. (2001) TUCAN, an antiapoptotic caspase-associated recruitment domain family protein overexpressed in cancer. J. Biol. Chem. 276, 32220-9.

Poyet, J. L., Srinivasula, S. M., Tnani, M., Razmara, M., Fernandes-Alnemri, T. and Alnemri, E. S. (2001) Identification of Ipaf, a human caspase-1-activating protein related to Apaf-1. J. Biol. Chem. 276, 28309-13.

Richards, N., Schaner, P., Diaz, A., Stuckey, J., Shelden, E., Wadhwa, A. and Gumucio, D. L. (2001) Interaction between Pyrin and the Apoptotic Speck Protein (ASC) modulates ASCinduced apoptosis. J. Biol. Chem. 276, 39320-9.

Srinivasula, S. M., Ahmad, M., Lin, J. H., Poyet, J. L., FernandesAlnemri, T., Tsichlis, P. N. and Alnemri, E. S. (1999) CLAP, a novel caspase recruitment domain-containing protein in the tumor necrosis factor receptor pathway, regulates NF- $\mathrm{KB}$ activation and apoptosis. J. Biol. Chem. 274, 17946-54.

Thome, M., Martinon, F., Hofmann, K., Rubio, V., Steiner, V., Schneider, P., Mattmann, C. and Tschopp, J. (1999) Equine herpesvirus-2 E10 gene product, but not its cellular homologue, activates NF- $\kappa \mathrm{B}$ transcription factor and c-Jun N-terminal kinase. J. Biol. Chem. 274, 9962-8.

Wang, L., Guo, Y., Huang, W. J., Ke, X., Poyet, J. L., Manji, G. A., Merriam, S., Glucksmann, M. A., DiStefano, P. S., Alnemri, E. S. and Bertin, J. (2001) Card10 is a novel caspase recruitment domain/membrane-associated guanylate kinase family member that interacts with BcL10 and activates NFkappaB. J. Biol. Chem. 276, 21405-9.

Yan, M., Lee, J., Schilbach, S., Goddard, A. and Dixit, V. (1999) mE10, a novel caspase recruitment domain-containing proapoptotic molecule. J. Biol. Chem. 274, 10287-92. 